\title{
Comparative Evaluation of Surface Treatment Effect of AZ91D Alloy Material
}

\author{
Sung-Hyung Lee ${ }^{1,2 *}$, Hitoshi Yashiro ${ }^{2}$ and Song-Zhu Kure-Chu ${ }^{3}$ \\ ${ }^{1}$ Gakkō hōjin Kitahara gakuen, Hirakawa 036-0146 Japan \\ 2 Department of Chemistry and Biological Science, Iwate University, Morioka, Iwate 020-8551 Japan \\ ${ }^{3}$ Materials Function and Design, Nagoya Institute of Technology, Nagoya, Aichi 466-8555 Japan
}

\begin{abstract}
Magnesium is chemically reactive, weakly corrosive, weakly abrasion resistant and heat resistant, so various surface treatments have been developed. Non-chromate, anodizing, and plasma anodizing were selected as the surface treatment methods, and a comparative study on surface components, oxide thickness, heat diffusivity, dielectric breakdown voltage, hardness, and corrosion resistance was conducted.

More specifically, the thermal conductivity is best in the case of non-chromate, and the breakdown voltage and Vickers hardness are highest in the case of plasma anodization. In the salt spray test, the corrosion resistance rating number was 3.5, 7, and 9 for non-chromate, anodization and plasma anodization, respectively.
\end{abstract}

Key Words: AZ91D Mg alloy, Anodization, Plasma anodization, Non-chromate, Oxide layer

\section{INTRODUCTION}

The magnesium is the lightest metal of utility metals, rich in resources, recyclable, and harmless to the human body. As a result, the application range of magnesium alloys is expanding in various industrial fields [1]..

Tables 1 and 3 show the types and processing methods of magnesium alloys; AZ91D alloys, in particular, are magnesium alloys that can be used in casting processes to improve efficiency and portability [Ref 1-9].

However, as shown in Figure 1, magnesium has the weakest potential among utility metals and is susceptible to corrosion, so surface treatment is essential for long-term use.

As shown in Tables 4 and 5, non-chromate and anodizing are currently used as surface treatment methods for magnesium alloys, especially AZ91D alloys, as a proven surface treatment method that eliminates environmental problems such as the use of chromic acid and fluoride poisonous materials [Ref 10-11]. Among them, plasma anodization is the most advanced technology in recent years [Ref. 1-3].

The purpose of the series of studies [Ref 1-3] was to develop and optimize procedures for stable oxide film formation in the plasma anodizing process.

This study compares the characteristics, structure and corrosion resistance of non-chromate and anodizing and plasma anodizing oxide films in the AZ91D alloy surface treatment process.

In order to select the surface treatment method to improve the performance of the AZ91D alloy, various factors such as the surface treatment process and the characteristics of the oxide film must be considered.

Table 1. Chemical composition of mg alloy cast (mass \%) Increase the resolution of the all tables

\begin{tabular}{|c|c|c|c|c|c|c|c|c|c|}
\hline Alloy & Element & Aluminum & Zinc & Copper & Manganese & Nickel & Silicon & Iron & Magnesium \\
\hline$A Z 31$ & Mass \% & $8.5-9.5$ & $0.45-0.90$ & $<0.025$ & $0.17-0.40$ & $<0.001$ & $<0.03$ & $<0.004$ & Balance \\
\hline AZ91 & Mass \% & 3 & 1 & 0.1 & 0.15 & 0.3 & - & - & Balance \\
\hline
\end{tabular}


International Journal of Advances in Scientific Research and Engineering (ijasre), Vol 5 (5), May-2019

Table 2. Comparison of the density among magnesium and other materials

\begin{tabular}{ccc}
\hline Materials & $\begin{array}{c}\text { Density } \\
\mathbf{g} / \mathbf{c m}^{\mathbf{3}}\end{array}$ & Comparison \\
& & \\
\hline Magnesium & 1.74 & 1 \\
\hline Cr-Mo & 7.85 & 4.51 \\
\hline Aluminum & 2.7 & 1.55 \\
\hline Titanium & 4.5 & 2.59 \\
\hline
\end{tabular}

Table 3. Comparison of processing characteristics of AZ91D alloy material

\begin{tabular}{l|c|c}
\hline \multirow{4}{*}{ Materials } & $\begin{array}{c}\text { AZ91D } \\
\text { Mg Casting }\end{array}$ & $\begin{array}{c}\text { AZ31 } \\
\text { Mg Press }\end{array}$ \\
\hline \multirow{4}{*}{ Process } & Diecasting & Mg Coil \\
\cline { 2 - 3 } & M.C (CNC) & Mg sheet \\
\cline { 2 - 3 } & Sanding & Press \\
\cline { 2 - 3 } & $\begin{array}{c}\text { Surface } \\
\text { Treatment }\end{array}$ & $\begin{array}{c}\text { Surface } \\
\text { Treatment }\end{array}$ \\
\cline { 2 - 3 } & Coating & Coating \\
\cline { 2 - 3 } & Assembly & Assembly \\
\cline { 2 - 3 } & & Con \\
\cline { 2 - 3 } & &
\end{tabular}

Table 4. Comparison of surface treatment processes of AZ91D alloy materials

\begin{tabular}{c|c|c|c|}
\hline $\begin{array}{c}\text { Surface } \\
\text { Treatment }\end{array}$ & $\begin{array}{c}\text { Non-chromate } \\
\text { Treatment }\end{array}$ & Anodizing & $\begin{array}{c}\text { Plasma } \\
\text { Anodizing }\end{array}$ \\
\hline \multirow{5}{*}{ Process } & Degreasing & Degreasing & Degreasing \\
\cline { 2 - 4 } & Activation & Activation & Activation \\
\cline { 2 - 4 } & Cleaning & Cleaning & Plasma anodizing \\
\cline { 2 - 4 } & Etching & Etching & \\
\cline { 2 - 4 } & Rinse & Rinse & \\
\cline { 2 - 4 } & Non-chromate & Anodizing & \\
\hline
\end{tabular}


International Journal of Advances in Scientific Research and Engineering (ijasre), Vol 5 (5), May-2019

Table 5. Comparison of characteristics of surface treatment process of AZ91D alloy materials

\begin{tabular}{|c|c|c|c|c|}
\hline $\begin{array}{c}\text { Surface } \\
\text { Treatment }\end{array}$ & Non-Chromate & Anodizing & 1 & Plasma Anodizing \\
\hline Cell voltage (V) & - & $20-80$ & $i$ & $120-300$ \\
\hline Current density, $/\left(\mathrm{A} \mathrm{dm}^{-2}\right)$ & - & $<10$ & $i$ & $<30$ \\
\hline Substrate Pretreatment & Critical & Critical & $\begin{array}{l}1 \\
1\end{array}$ & Less critical \\
\hline Common electrolytes & $\begin{array}{l}\text { Sulfuric acid, } \\
\text { Phosphoric acid }\end{array}$ & Alkaline & $\begin{array}{l}1 \\
1 \\
1\end{array}$ & Alkaline \\
\hline Thickness, d/ $\mu \mathrm{m}$ & $\sim 0.5$ & $\sim 10$ & 1 & $\sim 200$ \\
\hline Adhesion to substrate & Moderate & Moderate & 1 & Very high \\
\hline Temperature control & Critical & Critical & 1 & Less critical \\
\hline
\end{tabular}

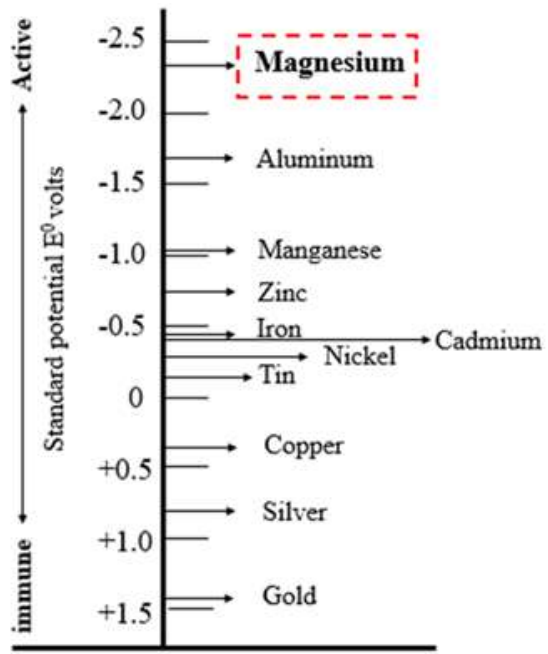

Figure 1. Electromotive force of magnesium

\section{EXPERIMENTAL METHOD}

In this study, the surface treatment method of plasma anodizing was used with the same electrolyte and test equipment and conditions as in the previous study [Ref 1-3]. Non-chromate used a common phosphate coating [Ref 15-16], and anodizing used phosphate-based low-voltage anodizing [Ref 13-14].

An AZ91D Mg alloy specimen having the chemical composition shown in Table 1 is used as a positive electrode (thickness: 12 $\mathrm{mm} ; 40 \mathrm{~mm}$ ).

The surface, thickness, cross section and composition of the surface-treated AZ91D samples were investigated using field emission scanning electron microscopy (FESEM). The test piece was cut, placed in a cool place, and polished with silicon carbide (SiC) paper.

The surface roughness was measured using a surface roughness tester (MITUTOYO, SJ-400). The measurement was carried out three times in an area of $0.8 \mathrm{~mm}$ for each specimen and the roughness average (Ra) was calculated. $R$ a represents the average surface roughness value from the measurement center line to the surface contour.

Samples (Model TOS5051A, KIKUSUI) were used to measure the dielectric breakdown voltage, and samples (Model LFA 457, Netzsch) were used to measure thermal conductivity.

In order to evaluate the hardness, samples were measured with a nanoindenter (Model ENT-1100b, Elionix)

Electrochemical impedance spectroscopy (EIS) measurements were performed using a $3 \mathrm{~mol} \mathrm{dm}-3 \mathrm{NaCl}$ solution using potentiostat/galvanostat (10 V/2A, ZIVE SP2, WonATech, Co.). The frequency response analyzer (FRA) was used to analyze the EIS output. In addition, a saltwater spray test was conducted according to the American Society for Testing and Materials (ASTM) -B117 standard test using a $5 \mathrm{wt} \% \mathrm{NaCl}$ solution maintained at $35^{\circ} \mathrm{C}$ for $72 \mathrm{~h}$. 


\section{RESULTS AND DISCUSSION}

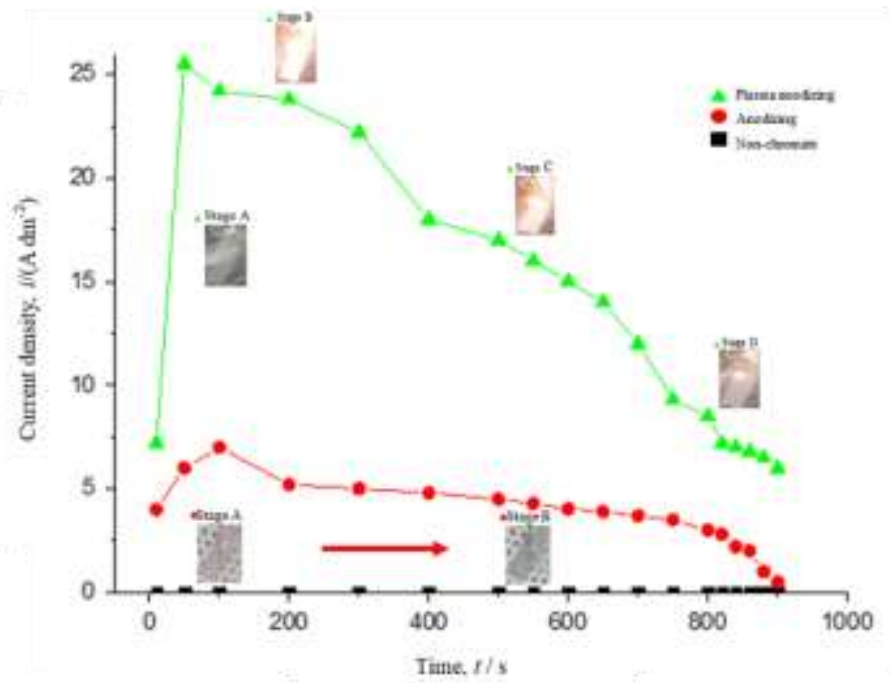

Figure 2. Typical variation of current density showing different stages of AZ91D surface treatment.

Figure 2 shows the change in the current and surface image during the surface treatment of the AZ91D material. The nonchromate treatment can be excluded by the immersion electroless method and the plasma anodizing and anodizing methods can be compared.

The plasma anodizing method proceeds from the step A to the step B-C where the maximum plasma is generated starting from the generation of the gas, and to the step D where the volume of the plasma is increased [Ref 3].

In the anodizing process, a fine plasma is generated along with gas generation in step A, and a step B is performed in which only a minute amount of gas is generated over time.

The anodizing process is a lower-voltage process compared to the plasma anodizing process. This is related to the conductivity of the two processes. 
(a)

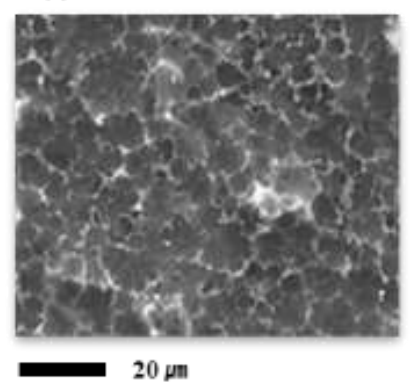

(b)

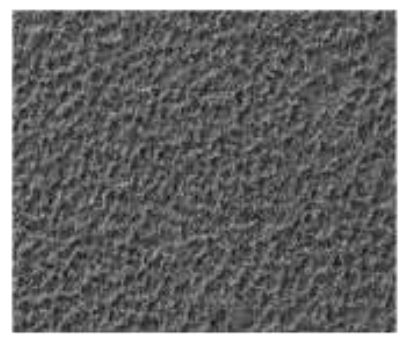

$20 \mu \mathrm{m}$

(c)

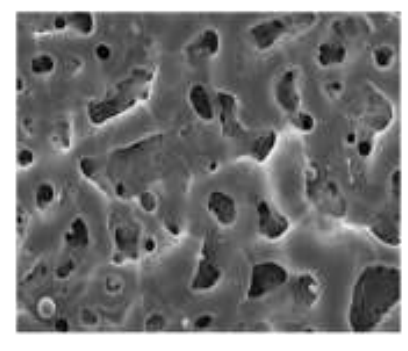

$20 \mu \mathrm{m}$

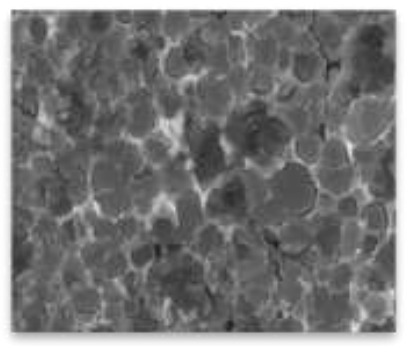

\begin{tabular}{|c|c|}
\hline Element & Mass \\
\hline $\mathrm{C}$ & 4.55 \\
\hline O. & 21.55 \\
\hline $\mathrm{Mg}$ & 58.84 \\
\hline Al & 3.24 \\
\hline P. & 676 \\
\hline $\mathrm{Ca}$ & 197 \\
\hline $\mathrm{v}$ & 1.81 \\
\hline $\mathrm{Zn}$ & 1.28 \\
\hline Totals & 100 \\
\hline
\end{tabular}

$10 \mu \mathrm{m}$

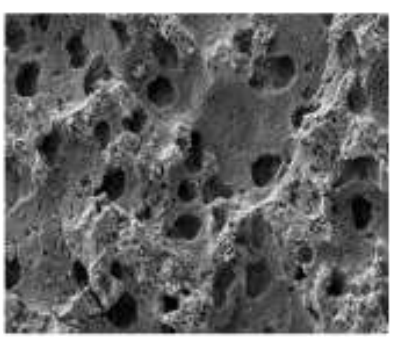

\begin{tabular}{|c|c|}
\hline Element & Mass \\
\hline $\mathrm{C}$ & 1.67 \\
\hline $\mathrm{O}$ & 41.93 \\
\hline $\mathrm{Mg}$ & 51 \\
\hdashline $\mathrm{Al}$ & 3.97 \\
\hline $\mathrm{Si}$ & 0.65 \\
\hline $\mathrm{P}$ & 0.78 \\
\hline Totals & 100 \\
\hline & \\
\hline
\end{tabular}
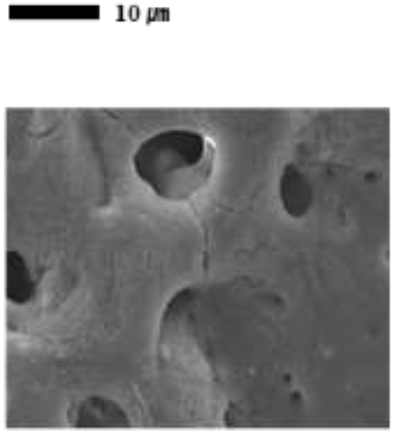

\begin{tabular}{|c|c|}
\hline Element & Mass \\
\hline c & 1.21 \\
\hline 0 & 59.25 \\
\hline $\mathrm{Mg}$ & 33.6 \\
\hline Al & 1.14 \\
\hline $\mathrm{Si}$ & 4.8 \\
\hline Totals & 100 \\
\hline
\end{tabular}

$10 \mu \mathrm{m}$

Figure 3. Surface morphologies and composition of AZ91D alloy materials after Non-chromate (b) Anodizing (c) Plasma anodizing
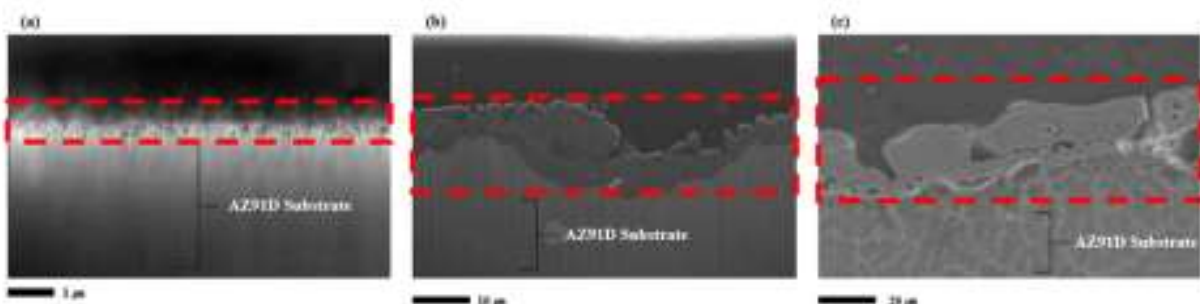

Figure 4. Cross sections of AZ91D alloy materials after Non-chromate (b) Anodizing (c) Plasma anodizing

Figure 3 shows the surface structure and composition of non-chromate, anodization and plasma anodization.

It was confirmed that $\mathrm{Mg}, \mathrm{O}$ and $\mathrm{P}$ were uniformly distributed in the result of the EDS element mapping showing the distribution of the oxide film component in the phosphate coating of the non-chromate. Since the FESEM image of the surface oxide is an electroless surface treatment method, the pores of the surface are not visible and the thin oxide layer is uniformly present.

In anodization and plasma anodization, $\mathrm{Mg}, \mathrm{O}$ and $\mathrm{Si}$ are uniformly distributed as the main components of the oxide film in all the EDS element mapping results indicating the distribution of the oxide film components.

In the plasma anodizing, the surface of the oxide layer showed a larger size of the pore. Applying a pulse voltage of $200 \mathrm{~V}$ results in greater non-uniformity and a larger pore size. The voids appearing on the surface are formed by the oxygen bubbles generated when microscale arcs are formed on the surface during the plasma anodizing process. Since the size of the microscale arc is proportional to the magnitude of the current, the higher the applied voltage, the larger the pore size [Ref 17]. 
The non-uniform growth pattern of the oxide film and the oxygen bubble trapping during the growth process lead to the formation of a wider porous layer in the ceramic layer.

Figure 4 shows a cross-sectional image of each specimen for observing the thickness of each oxide layer. The thickness of the non-chromate oxide film layer was confirmed to be $1 \mu \mathrm{m}$ or less. The anodized product had an oxide thickness of 5-10 $\mu \mathrm{m}$ and a plasma anodized product of 10-20 $\mu \mathrm{m}$ thickness. The thickness of the oxide film of the specimen treated with a $200 \mathrm{~V}$ voltage in the plasma anodizing surface treatment process is two or three times higher than that of the specimen treated at $50 \mathrm{~V}$. In addition, the size of the pores in the plasma anodized product was large and voids were confirmed in the cross section.

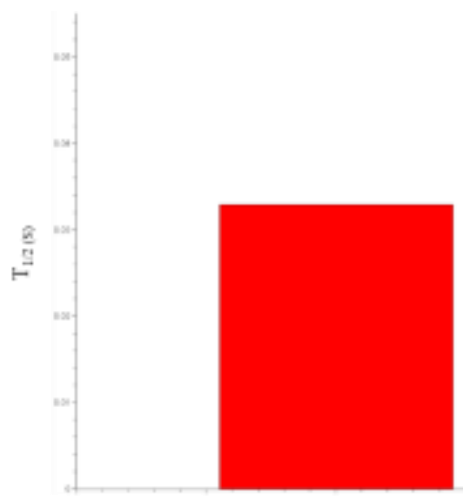

Non-chromate

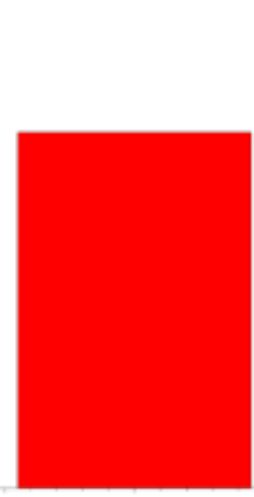

Anodizing

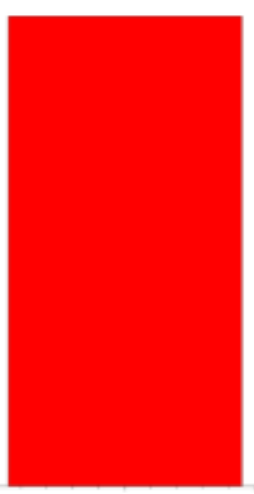

Plasma anodizing

Figure 5. Effect of AZ91D alloy materials surface treatment method on the thermal diffusivity

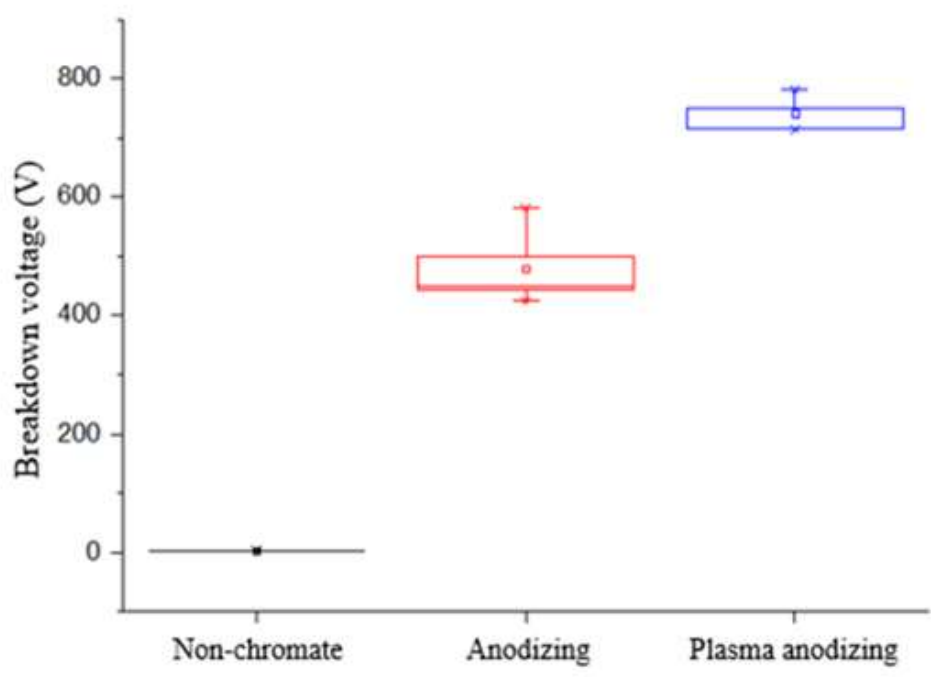

Figure 6. Effect of AZ91D alloy materials surface treatment method on breakdown voltage 


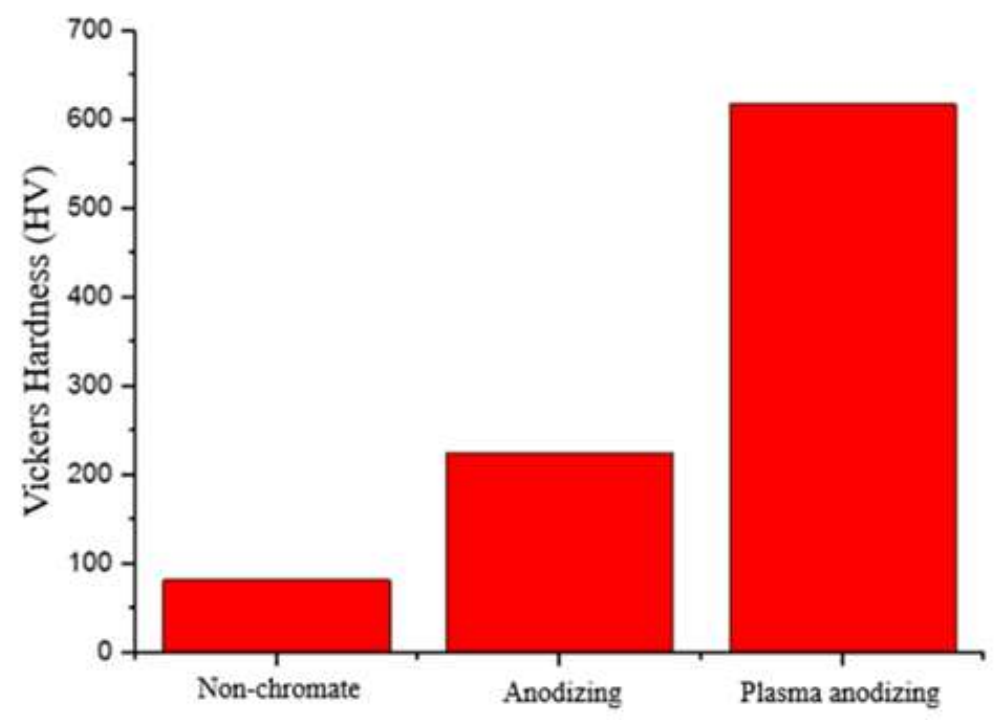

Figure 7. Effect of AZ91D alloy materials surface treatment method on the Vickers hardness

Figures 5 and 6 show the results of measurement of thermal diffusivity and thermal breakdown voltage of an oxide film formed on the surface treatment type of AZ91D alloy material.

In the case of the results of the measurement of the thermal diffusivity, the value of the result is lower in the order of nonchromate, anodization and plasma anodization. In addition, the results of the dielectric breakdown voltage measurements were inversely related.

It is found that this difference is due to the decrease in the thermal diffusivity and the increase in the breakdown voltage as the thickness of the oxide film increases.

Figure 7 shows the surface microhardness of AZ91D alloy material specimens by surface treatment type. The surface hardness of the non-chromate treated surface was $80 \mathrm{Hv}$, which is the same as that of the AZ91D alloy raw material, and this result was confirmed to be caused by the oxide film thickness of $1 \mu \mathrm{m}$ or less.

The surface hardness of the specimens treated under anodization and plasma anodization conditions were 230 and $620 \mathrm{Hv}$, respectively. Therefore, the surface hardness of the sample subjected to anodic oxidation was 3 to 8 times higher than that of the AZ91D alloy material and the non-chromate treated specimen.

The reason for the difference in surface microhardness of such specimens under the conditions of anodization and plasma anodization is that the conductivity of the electrolyte is different due to the concentration of the electrolyte.

It is suspected that a difference in the density of the oxide film due to the release of the oxygen gas has occurred due to the growth rate of the oxide film generated at different voltage and current density differences therebetween. Further research is planned to investigate this effect. 


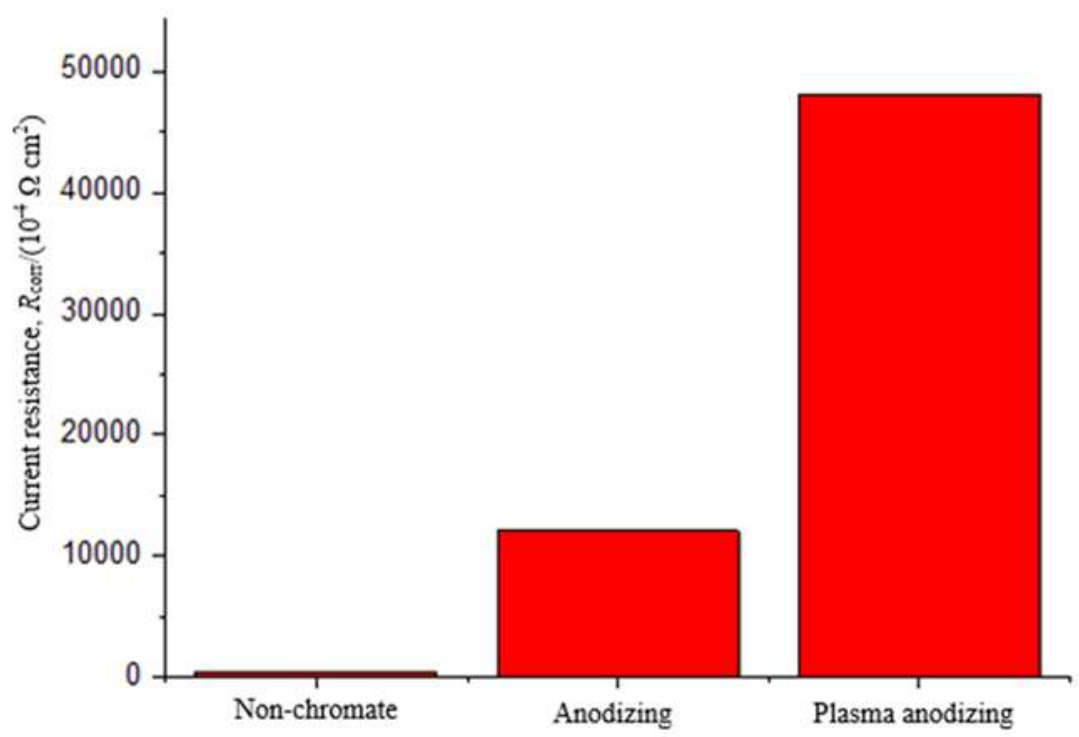

Figure 8. Effect of surface treatment method on the corrosion resistance of the treated AZ91D alloy materials. (solution: 3 mol dm-3 NaCl, temperature: $25^{\circ} \mathrm{C}$ )

Figure 8 shows the corrosion resistance of the sample measured with the 3 mol dm-3 NaCl solution using EIS as the type of surface treatment method. As expected, the corrosion resistance of the plasma anodizing method was the best. In this figure, the corrosion resistance value is related to the magnitude of the AC impedance at $10 \mathrm{~Hz}$, as this is usually dominant at this frequency. A board plot of the impedance indicates that the impedance is virtually constant if the magnitude of the impedance is lower than $10 \mathrm{~Hz}$.

\begin{tabular}{|c|c|c|c|}
\hline $\begin{array}{c}\text { Surface } \\
\text { Treatment }\end{array}$ & Non-chromate & Anodizing & Plasma Anodizing \\
\hline & RN 7 & RN 9 \\
C & N & & \\
\hline & & & \\
\hline
\end{tabular}

Figure 9. Surface images of the AZ91D alloy materials surface treatment method after the salt spray test (72 h).

Figure 9 shows the results of a salt spray test carried out for $72 \mathrm{~h}$ in accordance with ASTM standards to evaluate the corrosion characteristics of $\mathrm{Mg}$ alloys specimens by surface treatment of non-chromate, anodization and plasma anodization. The experiment was carried out using a $5 \mathrm{wt} \% \mathrm{NaCl}$ solution, and the temperature was maintained at $35{ }^{\circ} \mathrm{C}$. Corrosion properties were quantified by evaluating the average grade number (RN). The RN value of the non-chromate and anodizing surface treatment method was 3.5-7, while the plasma anodizing surface treatment method had an RN value of 9. These results reflect trends observed in EIS data (see Figure 8).

The oxide film formed by plasma anodization generally has a three-layer structure, of which the intermediate layer is the densest and most important in corrosion resistance [Ref 18].

\section{CONCLUSION}

We investigated the processing methods of $\mathrm{Mg}$ alloy materials and the types of surface treatment methods and compared the treatment results with AZ91D alloy. $\mathrm{Mg}, \mathrm{O}$, and $\mathrm{P}$ were detected in the non-chromate film, and $\mathrm{Mg}, \mathrm{O}$ and $\mathrm{Si}$ were uniformly 
distributed in the anodizing process and the plasma anodization process. In addition, there were no pores in the non-chromated surface, and there were pores in the anodizing and plasma treatment. In addition, the thickness of the oxide layer was less than 1 $\mu \mathrm{m}$, and the anodizing process and the plasma anodization process were confirmed to have an oxide thickness of 10-20 $\mu \mathrm{m}$. The results of the measurement of thermal diffusivity were excellent for non-chromate films, and plasma anodizing was the best for dielectric breakdown voltage.

In the measurement of surface microhardness, the values of non-chromate were $80 \mathrm{Hv}$, anodizing and plasma anodizing were 230 and $620 \mathrm{Hv}$, respectively. Based on this research, you can select a surface treatment method that is optimized for products using AZ91D materials.

\section{REFERENCES}

1.S.-H. Lee, H. Yashiro and S.-Z. Kure-Chu, Fabrication of Plasma Electrolytic Oxidation Coatings on Magnesium AZ91D Casting Alloys, J. Korean Inst. Surf. Eng., 2017, 50(6), p 432-438.

2.S.-H. Lee, H. Yashiro and S.-Z. Kure-Chu, Effect of Power Mode of Plasma Anodization on the Properties of formed Oxide Films on AZ91D Magnesium Alloy, Korean J. Mater. Res 2018, 28(10)

3. S.-H. Lee, H. Yashiro and S.-Z. Kure-Chu, Electrolyte temperature dependence on the properties of plasma anodized oxide films formed on AZ91D magnesium alloy, Korean J. Mater. Res 2019

4.B. L. Mordike and T. Ebert, Magnesium Properties-Applications-Potential, Mater. Sci. Eng. A, 2001, 302(1), p 37-45.

5.G. Song, A. Atrens, D. Stjohn, J. Nairn, and Y. Li, The Electrochemical Corrosion of Pure Magnesium in $1 \mathrm{~N} \mathrm{NaCl,} \mathrm{Corros.}$ Sci., 1997, 39(5), p 855-875.

6.Y. Ma, X. Nie, D. O. Northwood, and H. Hu, Systematic Study of the Electrolytic Plasma Oxidation Process on a Mg Alloy for Corrosion Protection, Thin Solid Films, 2006, 494(1), p 296-301.

7.J. Gray and B. Luan, Protective Coatings on Magnesium and its Alloys - A Critical Review. J. Alloys Compd., 2002, 336(1-2), p 88-113.

8.P. B. Srinivasan, C. Blawert, and W. Dietzel, Effect of Plasma Electrolytic Oxidation Treatment on the Corrosion and Stress Corrosion Cracking Behaviour of AM50 Magnesium Alloy, Mater. Sci. Eng. A, 2008, 494(1), p 401-406.

9.Y. Zhang, C. Yan, F. Wang, H. Lou, and C. Cao, Study on the Environmentally Friendly Anodizing of AZ91D Magnesium Alloy, Surf. Coat. Technol., 2002, 161(1), p 36-43.

10.MAKAR, G. L.; KRUGER, J1. Corrosion of magnesium. International materials reviews, 1993, 38.3: 138-153.

11.EMLEY, E. F. Principles of Magnesium Technology Pergamon Press. New York, London, 1966.

12.CHANG, Chin-Fong; DAS, Santosh K. Hot rolled sheet of rapidly solidified magnesium base alloy. U.S. Patent No 5,087,304, 1992.

13.F. A. Lowenheim, Modern Electroplating, Wiley, New York, 1974.

14.GRAY, JEl; LUAN, Ben. Protective coatings on magnesium and its alloys-a critical review. Journal of alloys and compounds, 2002, 336.1-2: 88-113.

15.GRAY, JEl; LUAN, Ben. Protective coatings on magnesium and its alloys - a critical review. Journal of alloys and compounds, 2002, 336.1-2: 88-113.

16.BRACE, A. Seventy years of sulphuric acid anodizing. Transactions of the Institute of Metal Finishing, 1997, 75: B101-B106.

17.Narayanan, T. S., Park, I. S., \& Lee, M. H. Progress in Materials Science,2014, 60: 1-71.

18.Y. Yan, Y. Han, D. Li, J. Huang, and Q. Lian, Effect of NaAlO2 Concentrations on Microstructure and Corrosion Resistance of A12O3/ZrO2 Coatings Formed on Zirconium by Micro-arc Oxidation, Appl. Surf. Sci., 2010, 256(21), p 6359-6366. 